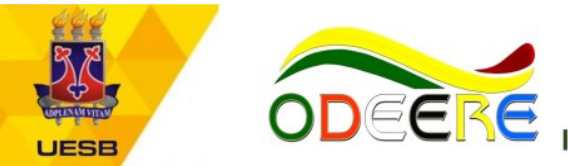

Revista do Programa de Pós-Graduação em

Relações Étnicas e Contemporaneidade

ISSN: 2525-4715 | DOI: 10.22481/odeere | revistaodeere@uesb.edu.br

\title{
Pedagogias de (re)existências do movimento de mulheres negras na Bahia em tempos de pandemia
}

\author{
Joana Maria Leôncio Núñez ${ }^{1}$ (i) \\ Universidade do Estado da Bahia \\ Jane Adriana Vasconcelos Pacheco Rios 2 \\ Universidade do Estado da Bahia \\ Artigos livres | Free articles | Articulos libres \\ DOI do artigo: 10.22481/odeere.v6i01.8500
}

\begin{abstract}
RESUMO
O texto apresenta experiências da Rede de Mulheres Negras da Bahia (RMNB) no âmbito da Pandemia do Sars-Cov2, em diálogos com as pedagogias de (re)existências construídas na/com a própria Rede. Trata-se de uma pesquisa em andamento, fundamentada nos estudos do feminismo negro e nas teorias decoloniais. A partir de narrativas inspiradas nas escrevivências de Conceição Evaristo, o estudo aponta o ativismo dos Movimentos de Mulheres Negras da Bahia e a construção de outras epistemologias que rompem com a geopolítica do conhecimento colonizado. O trabalho inscreve as primeiras incursões em uma (etno)grafia destas pedagogias de (re)existências produzidas por estas mulheres no contexto de enfrentamento a crise sanitária atual.
\end{abstract}

Palavras-chave: Movimento de mulheres negras, pedagogias de (re)existências, Pandemia.

\section{Pedagogies of (re)existences of the black women's movement in bahia in times of pandemic \\ ABSTRACT}

The text presents experiences of the Network of Black Women of Bahia (RMNB) in the context of the Sars-Cov2 Pandemic, in dialogues with the pedagogies of (re)existence built in/with the Network itself. This is an ongoing research, based on studies of black feminism and decolonial theories. Based on narratives inspired by the writings of Conceição Evaristo, the study points to the activism of the Black Women's Movements in Bahia and the construction of other epistemologies that break with the geopolitics of colonized knowledge. The work inscribes the first incursions in an (ethno)graphy of these pedagogies of (re)existence produced by these women in the context of confronting the current health crisis.

Keywords: Black women's movement, (re)existence pedagogies, Pandemic.

\section{Introdução}

\section{Submetido em: 22 de abr. de 2021 | Aceito em: 03 de jun. de 2021}

Este texto apresenta experiências e pedagogias de (re)existências de ativistas da rede de mulheres negras da Bahia no contexto da Pandemia. $\bigcirc$ estudo

\footnotetext{
1 Graduada em Psicologia pela UFRJ e Doutoranda e Mestre em Educação e Contemporaneidade pelo Programa de Pós-Graduação em Educação e Contemporaneidade (PPGEduC) da Universidade do Estado da Bahia, Linha de pesquisa (LPq) 2 Educação, Práxis Pedagógica e Formação do Educador, Integrante do Grupo de Pesquisa Docência, Narrativas e Diversidades. Professora da Universidade do Estado da Bahia, Auxiliar B. Atua principalmente na área de Formação de Professores com os seguintes temas: Relações étnico/raciais; de gênero e sexualidades; feminismo negro, pedagogias de resistência. Pesquisadora do Grupo de Pesquisas CANDACES, Grupo de Pesquisa sobre GÊNERO, RAÇA, CULTURA E SOCIEDADE (GPG). E-mail: immleoncio@hotmail.com

2 Doutorado e Pós-doutorado em Educação. Professora Titular Plena da Universidade do Estado da Bahia (UNEB). Professora Pesquisadora do Programa de Pós-Graduação em Educação e Contemporaneidade da Universidade do Estado da Bahia (PPGEDUC/UNEB). Líder do Grupo de Pesquisa Docência, Narrativas e Diversidade na Educação Básica (DIVERSO). Co-coordenadora da

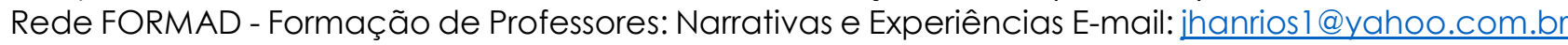


Nuñez, J. M. L.; Rios, J. A. V. P., Pedagogias de (re)existências do movimento de mulheres negras

parte da pesquisa de doutorado, que, embora não tenha ido a campo, já contém algumas incursões dentro dos movimentos de mulheres negras. A pesquisa doutoral propõe olhar o movimento de mulheres negras e voltar para pensar as práticas pedagógicas na educação básica, compreendendo o papel das pedagogias de resistências construídas por professoras negras ativistas da Rede de Mulheres Negras da Bahia. A referida pesquisa doutoral vincula-se a Pesquisa matricial: Profissão docente na Educação Básica da Bahia ${ }^{3}$, desenvolvida pelo Grupo de Pesquisa Docência, Narrativas e Diversidade na Educação Básica - DIVERSO que investiga os modos de habitar a docência entrecruzados pela diversidade (RIOS, $2021)^{4}$.

Teoricamente, a pesquisa doutoral está alicerçado nos estudos que abordam duas categorias epistêmico-políticas: pedagogias de resistência que são um conjunto de práticas pedagógicas que se articulam na academia e nos movimentos sociais, com o objetivo de provocar mudanças de narrativas e de agenciamento sócio histórico e o feminismo negro, criado a partir da experiência de mulheres negras, com ideias produzidas por mulheres negras, que divulgam a perspectiva singular como ponto de vista de/para mulheres negras como grupo 5 . Compõem esta discussão, sobretudo, as autorias protagonizadas por ativistas negras no cotidiano de suas práticas pedagógicas feministas negras, para refletir sobre pedagogias de resistência que florescem nas brechas da educação colonizada e se configuram em práxis e estratégias de intervenção e leitura de mundo.

A educação é caminho e estratégia para repensar o modelo educacional que reproduz discursos e práticas excludentes na escola e na sociedade, neste contexto as pedagogias de resistências se opõem as estruturas sociais, políticas e epistêmicas racistas, sexistas, LGBTfóbicas e neoliberais, as quais disseminam a reprodução, difusão e construção de hierarquias de poder que subalternizam principalmente mulheres e homens negros. Pedagogias de resistência não se limitam ao campo da educação, suas metodologias são concebidas principalmente nas lutas sociais de libertação política, ontológica, epistêmica

\footnotetext{
3 Pesquisa financiada pela Chamada Universal MCTI/CNPan ${ }^{\circ}$ 28/2018.

${ }^{4}$ RIOS, 2020.

${ }^{5}$ COLLINS, 2016.
} 
Nuñez, J. M. L.; Rios, J. A. V. P., Pedagogias de (re)existências do movimento de mulheres negras

construída em espaços sociais de resistência. Estas pedagogias assumem que aprendizagem, (des)aprendizagem, (re)aprendizagem, reflexão e ação se iniciam com oposição à condição de dominação e opressão colonial. Organizam e intervém coletivamente, na formação e ação política sobre as condições impostas pela colonialidade, transformando padrões de poder na sociedade.

Podemos criar uma educação libertadora e emancipadora e apesar da educação não ser um paraíso, pode ser o lugar onde o paraíso é criado. Para hooks (2013), a sala de aula com todas as suas limitações continua sendo um campo de possibilidades e neste ambiente temos a oportunidade de trabalhar pela emancipação, que exige de nós uma abertura de mente e coração, permitindo encarar a realidade, ao mesmo tempo em que coletivamente formulamos estratégias para uma educação transgressora, a educação como prática de liberdadé.

A RMNBA, articulação feminista de esquerda composta de ativistas, entidades, coletivos, grupos acadêmicos, culturais, educativos e artistas, com diversas orientações políticas, sexuais e religiosas, considera a educação como caminho para construção e afirmação de direitos, reconhecimento e valorização da história cultural das mulheres negras na busca do Bem Viver, conceito que nasce da sabedoria ancestral africana e indígena e compreende as concepções de gestão do coletivo e individual, da natureza, da política, cultura, educação e existência.

Nosso entendimento é que os espaços educacionais dos movimentos sociais são espaços de aprendizagem para todas/os que transitam neles e, embora a educação seja parte importante neste contexto, muitos desses aprendizados são realizados em situações que escapam ao mundo da aprendizagem formal e da produção de conhecimentos na academia. Há também uma outra educação, realizada a partir dos movimentos de mulheres nos quais se constrói a inter-relação e o contato com a ação educativa, cultural e política. Este processo, iniciado com a virada epistêmica decolonial, considera que a educação tem importante influência na formação, política coletiva, solidária, edificada no interior dos movimentos sociais, principalmente nos Movimentos de Mulheres Negras (MMN).

6 HOOKS, 2013. 
Nuñez, J. M. L.; Rios, J. A. V. P., Pedagogias de (re)existências do movimento de mulheres negras

A partir da crise sanitária que se instalou no país com a Covid19, lideranças da Rede de Mulheres Negras da Bahia (RMNBA) se organizaram em uma verdadeira batalha para agilizar, entre outras coisas, documentação para receber o auxílio emergencial do governo; oferecer formação política, acolhimento, cuidado afetivo; compartilhar experiencias exitosas diante do quadro grave de saúde, miséria e morte que se abateu sobre o país. Foi um movimento de respiro que oxigenou as coletivas no propósito de refletir e apontar caminhos para que mulheres negras e suas organizações se movimentassem frente a Pandemia.

Diante deste contexto, este artigo pretende discutir o ativismo dos MMN da Bahia e a construção de outras epistemologias que rompem com a geopolítica do conhecimento colonizado, racista, misógino, LGBTfóbico, apontando para o potencial insurgente, de resistência e transformação resultantes do ativismo nesses movimentos nos tempos de Pandemia. O trabalho com as narrativas é inspirado nas escrevivências de Conceição Evaristo que concebe este movimento como "a escrita de um corpo, de uma condição, de uma experiência"7.

Este artigo está distribuído em três partes nas quais discutimos inicialmente o lugar do movimento negro na construção de pedagogias de luta e (re)existência; em seguida tratamos da discussão sobre as pedagogias de (re)existências na Educação a partir da abordagem decolonial; e, por fim, apresentamos algumas narrativas de ativistas da RMNBA em suas disputa/rasura, nos micro espaços a partir de suas experiências pedagógicas durante a pandemia inscritas em seus pertencimentos e, consequentemente, em suas pautas de luta.

\section{Algumas escavações de uma história de resistência e luta}

Escavações históricas indicam que as pautas de resistência do povo negro que remontam a escravidão, foram marcadas pela rebeldia escrava. $O$ trabalho escravo trouxe consigo uma luta que assumiu diversas formas, como: a desobediência sistemática, a lentidão e sabotagem na execução das tarefas, fugas individuais ou coletivas, fundação de quilombos etc. As revoltas se repetiram durante os séculos XVIII e XIX e foram promovidas por africanas/os principalmente

7 EVARISTO, 2008, p. 20. 
Nuñez, J. M. L.; Rios, J. A. V. P., Pedagogias de (re)existências do movimento de mulheres negras

de origem nagô muçulmana, entre iorubás, como haussás, malês etc. ${ }^{8}$. Até o fim do período colonial a resistência e luta contra a escravização foi intensa, e, apesar de toda a repressão sofrida contra o povo negro escravizado e integrantes antiescravistas, ela prosseguiu e se fortaleceu ao longo do século XIX. Embora este processo tenha sido crucial, não foi suficiente para a descolonização da sociedade brasileira. os anos 1970, estudos sistematizados por Hasenbalg9; Carneiro e Santos 10 revelam que um dos grandes embates do Movimento Negro (MN) consistia em denunciar o mito da democracia racial indicando a desigualdade nas relações sociais entre brancos e negros em nível econômicopolítico-social. Abdias do Nascimento chama atenção para a forma pela qual a colonização se articulou e se manifestou através da bastardização da cultura afrobrasileira ${ }^{11}$ que revelou o embranquecimento cultural e estético como uma das principais formas de genocídio do negro no Brasil. O jornal Quilombo, fundado por Nascimento, deu uma contribuição valiosa para a conquista da autoestima e da cidadania. Exaltava a beleza e a inventividade da cultura negra, destacava a importância da educação para a imagem positiva do povo negro, explicava que os brancos detinham os meios de comunicação, possuíam o controle da produção brasileira, da educação, da formação e transmissão do conhecimento, ou seja: formulavam os conceitos, as armas e os valores do país e poderiam disseminar as informações que quisessem.

A perspectiva particular do homem branco, cristão, classe média e heterossexual foi naturalizada de tal forma como norma universal na produção de conhecimento, que qualquer conhecimento fora desta norma geopolítica de conhecimento, foi descartado como conhecimento não objetivo, parcial, particular, que não refletia a realidade. Historicamente, inexistiu uma transformação significativa do trabalho entre centro e periferia, bem como na hierarquia étnico-racial de populações, o que aconteceu foi uma transição de colonialismo moderno à colonialidade global (QUIJANO 12, MALDONADO

\footnotetext{
8 NASCIMENTO, 2016, p. 111

9 HASENBALG, 2005 [1979].

10 CARNEIRO, S.; SANTOS, T 1985.

11 Ibidem, 2016, p. 111

12 QUIJANO, 2000, 2005 1-14.
} 
Nuñez, J. M. L.; Rios, J. A. V. P., Pedagogias de (re)existências do movimento de mulheres negras

TORRES ${ }^{13}$ ). A relação entre modernidade-colonialismo-capitalismo criou um parâmetro mundial de poder e uma disputa sobre o controle e domínio do trabalho, natureza, riqueza, recursos, produção, subjetividade, juntamente com seus instrumentos de coerção e dominação social. Mesmo após o fim do colonialismo, o homem branco heterossexual cristão foi mantido como parâmetro, em um sistema de dominação raça/etnia, gênero, classe e sexualidade hierarquicamente imposto entre brancos/as, indígenas, negros/as, amarelos/as, mestiços/as, além da organização geocultural, entre Américas, Europa, África, Extremo Oriente, Próximo Oriente, Ásia etc. (GROSFOGUEL ${ }^{14}$ ).

No Brasil, a década de 1970 representa o momento em que os movimentos sociais buscam ruptura política, econômica, cultual, educacional e tomam a cena pública lutando contra a ditadura militar, pela redemocratização e pelo direito à cidadania da parcela excluída da população. Os governos militares negavam o racismo alegando questões de segurança nacional. Este período se configurou como de oposição política, denuncia e desmistificação da chamada democracia racial, mito criado ao logo da história para reforçar a narrativa de um Brasil onde havia "paz e harmonia" entre as raças, facilitando a dominação política, econômica, cultural pelo grupo hegemônico.

Lélia Gonzalez15, referência para diversos movimentos sociais, sobretudo antirracistas e feministas, em uma discussão sobre racismo e processo de exclusão dos negros no mercado de trabalho organizado por Beatriz Nascimento em 1973 , pelo Centro de Estudos Afro-asiáticos - (CEAA) da Universidade Cândido Mendes, apresenta o movimento negro (MN) como responsável pela desconstrução do mito da democracia racial. Neste período tem início uma série de mudanças, há muito reivindicadas por ativistas, intelectuais, acadêmicas/os, jornalistas, juristas, educadoras/es negras e negros. Ansiosos por debater as demandas de cunho identitário e redistributivo, estes movimentos demonstraram a indissociabilidade entre o mito da convivência pacífica entre raças e o racismo que estrutura a sociedade brasileira. O MN contemporâneo passa a novo sujeito coletivo e político, juntamente com outros movimentos sociais que organizam estratégias de

\footnotetext{
13 MALDONADO-TORRES, 2019.

14 GROSFOGUEL, 2019.

15 GONZALEZ, 1983.
} 
Nuñez, J. M. L.; Rios, J. A. V. P., Pedagogias de (re)existências do movimento de mulheres negras

resistência política, práticas pedagógicas de reconhecimento, debates, reflexões e interpelações em meio a articulações por novos caminhos, significados, ações e por uma sociedade mais justa (RODRIGUES, 2012). Neste sentido, Lélia ${ }^{16}$ propõe um feminismo das ladino amefricanas, combinando a perspectiva multirracial e pluricultural e promova o debate sobre o resultado dos processos históricos e contemporâneos de opressões interseccionais apontando saídas para a situação das mulheres amefricanas.

O MN se torna responsável por organizar e sistematizar a gramática de saberes específicos construídos coletivamente pela população negra em sua experiência social, cultural, ancestral, histórica, política e educacional no cenário político, configurando-se em um dos principais mediadores entre a comunidade negra, O Estado, a sociedade, a escola básica e a Universidade. No âmbito educacional, o MN e o Movimento de Mulheres Negras (MMN) propõem a formação político-pedagógica acerca da cultura e história em África e na Diáspora, no entendimento de que a luta antirracista, antissexista e pela diversidade cultural e religiosa travada na educação, pode descolonizar a sociedade brasileira, tão racista e preconceituosa.

Gomes ${ }^{17}$ destaca a importância de compreender a potência dos movimentos negros como uma dimensão que desvela seu caráter emancipatório, reivindicatório e afirmativo, ao se caracterizar como importante ator político, como educador de pessoas, coletivos e instituições sociais ao longo da história. A educação não é um campo imparcial, é um espaço sociocultural e político de convivência onde existem conflitos, tensões, contradições, discriminação racial, de gênero e de classe que fazem parte da cultura e da estrutura de nossa sociedade, fundada e sustentada sob o racismo, representada em relações de poder desiguais.

Em termos pedagógicos os movimentos sociais, principalmente os $M N$ e MMN, configuram-se como espaço de formação e fortalecimento de identidades oferecendo apoio, autoconfiança, autovalorização, autocuidado, autorrespeito, promovendo saberes significativos para a comunidade. Gohn (2011) evidencia que os movimentos sociais assumem uma concepção de educação que não se

\footnotetext{
16 GONZALEZ, 1988.

17 GOMES, 2017. $154 \mathrm{p}$.
} 
Nuñez, J. M. L.; Rios, J. A. V. P., Pedagogias de (re)existências do movimento de mulheres negras na Bahia em tempos de pandemia. ODEERE, v. 6, n. 01, jan./jun., p. 287-310, 2021. https://doi.org/10.22481/odeere.v6i01.8500

resume à escola, há aprendizagens e produção de saberes em outros espaços, de educação não formal em uma concepção ampla de educação, como os espaços de participação social em movimentos e ações coletivas que se constroem na educação popular e política.

Mediante muita pressão política e muita militância realizada ao longo dos últimos anos pelos movimentos negros e movimentos de mulheres negras, foram alcançados ganhos no sentido de forçar ações de reparação para superação das desigualdades na adoção de políticas públicas institucionalizadas por lei, (tais como: inserção na Constituição Federal do Artigo 68 das Disposições Transitórias, do reconhecimento de títulos de terra aos remanescentes das comunidades dos Quilombos, Lei 7.716/8918, que define "práticas de crime de racismo no Brasil", Lei 10.639/0319 que altera a LDB e estabelece a obrigatoriedade da inclusão de história e cultura afro-brasileira e africana no currículo da educação básica no país; Lei 12288/10 do Estatuto da Igualdade Racial20, Lei 12711/12 do estabelecimento de Cotas Sócio raciais nas Instituições Federais de Ensino Superior21; Lei 12990/14 das Cotas nos Concursos Públicos Federais 22 etc.). Assim, a raça foi tomada como critério para enfrentar as desigualdades, exclusões e forçar a reparação racial e social.

A SEPPIR (Secretaria da Promoção pela Igualdade Racial) e a SECAD (Secretaria de Educação Continuada, Alfabetização e Diversidade) foram criadas justamente para planejar, orientar e acompanhar a formulação e implementação de políticas educacionais antirracistas tendo em vista a diversidade de grupos etnicorraciais, como as comunidades indígenas, as populações afrodescendentes

\footnotetext{
18 BRASIL. Decreto lei 7716, de 5 de janeiro de 1989. Define os crimes resultantes de preconceito de raça ou cor. Disponível em <http://www.planalto.gov.br/ccivil_03/lei/17 7161/htm> Acesso em 20 de janeiro de 2021.

19 BRASIL. Lei 10.639/2003, de 9 de janeiro de 2003. Altera a Lei n 9. 394, de 20 de dezembro de 1996. Diário Oficial da União, Poder Executivo, Brasília.

20 BRASIL. LEI No 12.288, DE 20 DE JULHO DE 20103 Institui o Estatuto da Igualdade Racial; altera as Leis nos 7.716, de 5 de janeiro de 1989, 9.029, de 13 de abril de 1995, 7.347, de 24 de julho de 1985, e 10.778, de 24 de novembro de 2003.

${ }^{21}$ BRASIL. LEI N 12.711, DE 29 DE AGOSTO DE 2012 (Lei de Cotas de Ingresso nas Universidades) Dispõe sobre o ingresso nas universidades federais e nas instituições federais de ensino técnico de nível médio e dá outras providências. Publicação: DOU-1 de 30-8-2012, p. 1.

22 BRASIL. LEI No 12.990, DE 9 DE JUNHO DE 2014. Reserva aos negros $20 \%$ (vinte por cento) das vagas oferecidas nos concursos públicos para provimento de cargos efetivos e empregos públicos no âmbito da administração pública federal, das autarquias, das fundações públicas, das empresas públicas e das sociedades de economia mista controladas pela União.
} 
Nuñez, J. M. L.; Rios, J. A. V. P., Pedagogias de (re)existências do movimento de mulheres negras

dos meios urbano e rural, as comunidades das áreas remanescentes dos quilombos. Posteriormente a SECAD promoveu experiências de todos os tipos de políticas educacionais por organizações dos movimentos negros a exemplo do financiamento estudantil e o programa de bolsas e auxílio de permanência de estudantes nas Universidades.

O MMN defende o fortalecimento da educação na sociedade, com o propósito de viabilizar pedagogias insurgentes em correspondência políticoepistêmica-ética com vistas à criação de outra sociedade e de outra educação: democrática, antirracista, culturalmente múltipla e sustentável, incorpora discussões sobre direitos humanos, desigualdade, promoção da igualdade racial, equidade de gênero, justiça social, solidariedade, autonomia, constituição coletiva dos sujeitos etc. Esta luta, desde meados do século XX, inspirou gerações de intelectuais e ativistas que atuavam em várias frentes na educação, cultura, artes, esportes, ciências, política, jurídica etc. e repercutiu na articulação de convênios e projetos educacionais reivindicando a ação do Estado na garantia de oportunidades iguais e direito à educação. O ativismo que assumiu a dianteira na defesa e valorização da história e cultura da comunidade negra e lutou por políticas de ações afirmativas, democratização e acesso ao ensino público e gratuito, garantia e permanência na educação básica, acesso as Universidades teve como protagonista os movimentos de mulheres e homens negros.

\section{É tempo de aquilombar: pedagogias de (re)existência}

A escola é um texto carregado de significações, tensões, oposições binárias, hierarquizações, relações de poder; herança do paradigma educacional colonial. As pedagogias de resistências praticadas por ativistas e professoras negras alinhadas politicamente nos movimentos de mulheres negras e outros movimentos sociais, busca descontruir discursos que estruturam valores e ideologias que subalternizam e colocam pessoas em lugares inferiores. A desconstrução de pedagogias hegemônicas e excludentes requer um deslocamento da norma para a insurgência, requer valorização profissional, e a ideia de que a educação tem muitas faces, sentidos e é um importante espaço de interrelações e desconstrução de hierarquias sociais. 
Nuñez, J. M. L.; Rios, J. A. V. P., Pedagogias de (re)existências do movimento de mulheres negras

Quando a gente pensa pedagogias de resistências, considera o legado dos movimentos sociais principalmente os Movimentos de Mulheres Negras, mas também o Movimento Negro, o Movimento Sem-Terra, os Movimentos Indígenas, Artísticos e Culturais etc. Diferentes intelectuais em grupos acadêmicos produzem, atuam e constroem micropolíticas para inserir brechas e fissuras nas estruturas de poder da colonialidade. As pedagogias de resistências dos movimentos de mulheres negras movimentam-se para responder a demanda local em processos descolonizadores oferecendo novos caminhos à tarefa da educação, no sentido de dialogar e repactuar com a sociedade em outras bases políticas, epistêmicas, educacionais, econômicas etc.

A RMNBA se configura como espaço de discussão política sobre raça, gênero etc. Um quilombo educacional capaz de resistir e construir coletivamente o projeto do feminismo negro que enfrente, desestruture e destrua os muros da colonialidade. Nos aquilombamos para resistir a uma sociedade escravista, racista, misógina, cis-hetero-normativa, para reinventarmos próxis, teoria, ativismo, formação docente, luta política e afetividade em espaços de resistência coletiva, convivência, produção material e imaterial de conhecimento em novas alternativas para pensar o futuro.

Os MMN, diante do caos econômico, político, sanitário que vem ocorrendo em nosso país, comunica aos "donos do poder" que a luta política, a resistência, os corpos insubmissos, reconstrução comunitária, festa coletiva, não é incompatível com a luta contra o ciclo histórico que o país atravessa: "Quem foi Cabocla/o de julho" sempre ocupará a comissão de frente da história popular coletiva e de (re)construção política. Para pensar sobre a potência da resistência como ação coletiva nos tempos atuais, um pensamento é necessário. De quais armas dispomos para a luta, senão as estratégias de organização, resistência, formação política, conscientização para as nossas? As Pedagogias de Resistencia dos MMN indicam que a saída deste abismo, é a resistência e a subversão, pois não há aceitação possível àquilo que está sendo reservado ao nosso povo.

Historicamente organizações dos MMN e outros movimentos sociais incentivaram a formação política, educacional e cultural de seus membros construindo estratégias de ocupação e luta em redes visíveis e invisíveis de formação, luta política, em seus diversos formatos dentro e fora dos movimentos 
Nuñez, J. M. L.; Rios, J. A. V. P., Pedagogias de (re)existências do movimento de mulheres negras na Bahia em tempos de pandemia. ODEERE, v. 6, n. 01, jan./jun., p. 287-310, 2021. https://doi.org/10.22481/odeere.v6i01.8500

sociais. Um mergulho sobre nossa experiência coletiva indica que o MMN atua em rede construindo saberes pedagógicos advindos dos ensinamentos teóricos do feminismo negro que presume uma dimensão coletiva de ativismo com raízes na ancestralidade africana, nos ensinamentos do candomblé, que sobreviveram pela oralidade, mesmo com toda a perseguição às religiões de matriz africana. Nossa história nos conta que a organização coletiva é a única saída possível para garantir a sobrevivência. A afetividade e o cuidado que atravessa nossos corpos torna possível nossa existência, pois, somos teimosas, insurgentes, criativas e construímos formas políticas, culturais e pedagógicas de (re)existir às desigualdades que nos interpelam. O poder da mulher negra no conhecimento das plantas, da natureza, no cuidado com a coletividade na transmissão dos conhecimentos, dos costumes cria formas de convivência que garantem, desde os tempos da escravidão, a sobrevivência e a capacidade de aglutinar, resistir, fazer política, lutar contra opressões, buscar alianças com outros grupos e movimentos sociais. Estas formas de atuação foram fundamentais para a consolidação do ativismo e são responsáveis por agregar a população racializada nos tempos atuais na luta contra este projeto político civilizatório.

Para Figueiredo23:

Há uma relação entre o movimento político liderado pelas mulheres nos anos 1970 e a produção acadêmica na tentativa de compreensão da opressão feminina e na relação sexo biológicogênero, entendido sempre como uma construção social. Testemunhamos o aumento significativo do feminismo negro e suas diferentes perspectivas: são as feministas negras decoloniais, feministas negras abolicionistas, feministas negras interseccionais, feministas negras lésbicas, dentre outros. Esse movimento tem sido autodefinido pelas mulheres negras em Salvador como maré feminista negra, uma clara alusão à divisão das três fases que caracterizam o feminismo em ondas; ao mesmo tempo em que se constitui enquanto uma ruptura, uma vez que as diferentes ondas feministas não incluíram, em nenhuma de suas fases, a contribuição feminista negra.

O compromisso com a educação assumido pelas mulheres negras estampado no reconhecimento de muitas lideranças que reverenciam suas mães

23 FIGUEIREDO, 2020, p.4. 
Nuñez, J. M. L.; Rios, J. A. V. P., Pedagogias de (re)existências do movimento de mulheres negras

e avós como responsáveis por sua construção intelectual, algumas vezes trabalhando como lavadeiras, domésticas, costureiras, para famílias brancas, no intuito de fazerem-nas as primeiras da família a "ir para a faculdade".

Vilma Reis, ativista do movimento de mulheres negras da Bahia, defensora dos direitos humanos, das mulheres, negros e LGBTI, sempre agradece à ancestralidade ao fato de ter sido a "primeira pessoa da família a frequentar uma Universidade"24, em relato sobre a oportunidade de ter se tornado Socióloga e Ouvidora-geral da Defensoria Pública do Estado da Bahia, orgulha-se de exercer influência sobre outras tantas mulheres negras e ser exemplo para tantas jovens. Sempre agradece a sua família pela oportunidade de formar-se em São Lázaro (Faculdade de Ciências Sociais da Universidade Federal da Bahia) e reforça que o espaço da Universidade sempre foi mantido à distância, por vários muros de seletividade que impediam o acesso a ele, dentre os quais o do racismo e discriminação racial. A colação de grau, segundo Vilma Reis, foi o momento de arrombar a porta e entrar, para frequentar a Universidade, inclusive de sua família assistir sua solenidade de formatura. O Campus foi o quintal de sua casa, foi sonho e realidade, sonho, porque era a possibilidade de fugir do trabalho doméstico, e a realidade concretizada pela inacessibilidade, descreve Vilma.

A educação desempenhou este papel importante no ativismo, qualificação da intervenção política e possibilitou que "muitas construíssem uma rede de incentivo e apoio para o próprio grupo de militância, visando aprofundar os estudos e, principalmente, romper com a objetificação imposta pela sociedade"25, ressalta Benilda Paiva. Ativistas negras como Vilma e Benilda referem-se à influência da família como incentivadora da formação escolar, assumindo que as mulheres negras sempre souberam a importância da educação para o desenvolvimento de suas comunidades e encorajaram suas filhas e filhos a ir em busca de instrução, frequentar a escola e ter grandes expectativas. Mesmo que, na maioria das vezes, tivessem pouca instrução ou fossem analfabetas, entendiam a educação como instrumento poderoso para libertação do povo negro e pobre e, por isso, levaram a sério a crença na educação como instrumento para a elevação da raça.

24 CARDOSO, 2012. P 55

25 Ibidem, p.155 
Nuñez, J. M. L.; Rios, J. A. V. P., Pedagogias de (re)existências do movimento de mulheres negras

Freire 26 destaca que não existe neutralidade na educação: ou ela funciona como instrumento colonizador de mentes obedientes e alienadas ou ela é o meio pelo qual homens e mulheres lidam de forma crítica com a realidade e descobrem como participar da transformação do mundo. Graças às políticas públicas que democratizaram o acesso ao Ensino Superior, formuladas entre 2002 e 2015, houve uma geração de jovens que teve acesso às universidades. Na contradição apontada por Freire 27 em "Pedagogia do Oprimido": "hospedamos" o opressor está dentro de nós, Freire explica que esta contradição só pode ser desfeita se, e quando, descobrirmos que somos "hospedeiros" do opressor, indo em busca da "cura", que passa pela luta política coletiva e organizada nas ruas, na academia, nos movimentos sociais, nos sindicatos, por uma sociedade justa e uma educação emancipadora.

Concebemos que as pedagogias de resistência, são o conjunto de processos políticos, socioculturais, educacionais, artísticos e civilizatórios com diferentes formas de lutas por igualdade, direito à vida, corporeidade, entre outros, que inserem estruturas sociais de poder, de ser, de saber e aprender vinculadas à experiência coletiva docente e aos saberes desenvolvidos em diálogo com os movimentos sociais. Elas potencializam e favorecem o conhecimento socialmente legitimado por novos protagonistas em novos modelos de pertencimento. Há nestas pedagogias o reconhecimento, valorização, respeito das diferenças, a cooperação, interação social, diálogo entre sujeitos, reconhecimento dos saberes locais originados na multirracialidade e na pluriculturalidade.

Gostaríamos de chamar a atenção para a presença e dinâmica organizacional comunitária onde as mulheres negras têm tecido e provocado uma importante transversalidade. Observamos com lupa o acúmulo dessas lutas que foram confrontadas com o modelo de educação racista, cis-hetero-normativa e colonizadora. Valorizamos pedagogias de escopo epistemológico desobediente, contra hegemônico, travadas nas grietas das estruturas de opressão que tornam possíveis outras formas de ser, estar, pensar, saber, sentir, existir e viver-com produzidos em contextos de insubmissão, resistência e (re)existência.

\footnotetext{
26 FREIRE, 2014.

27 FREIRE, 1987
} 
Nuñez, J. M. L.; Rios, J. A. V. P., Pedagogias de (re)existências do movimento de mulheres negras

\section{Rede de Mulheres Negras da Bahia}

O Movimento de Mulheres Negras (MMN) oferece suas experiências coletivas para pensar uma outra dinâmica de vida e ação política, que só é possível por meio da superação do racismo, do sexismo e de todas as formas de discriminação, e são responsáveis pela negação da humanidade de mulheres e homens negros. As ações e estratégias de resistência que caracterizam a RMNBA incluem formas e concepções de ativismo político que destacam como estas mulheres vivenciam injustiças e opressões interseccionadas por raça, gênero, classe social, sexualidade, idade, deficiência etc. O ativismo político produzido na MMN exerce uma relação dialética proporcional à incidência de eixos de dominação; quanto mais opressão recai sobre o grupo, mais resistência é deslocada e mais ativismo político é dado como resposta.

Para Davis 28 , as mulheres negras sempre tiveram fome de conhecimento e revolução como bandeira, pois, estão posicionadas na base da pirâmide social. Isto significa que mulheres negras, antes de pensarem em si mesmas como mulheres, pensam como comunidade, pois quase sempre assumem o lugar de liderança ou chefes de família. Segundo dados do Instituto de Pesquisa Econômica Aplicada (IPEA) ${ }^{29}$, no Brasil $42 \%$ das famílias são chefiadas por mulheres negras, ou seja: na vida social, mulheres negras assumem papéis de liderança em suas comunidades, na ocupação do território, em relação ao conhecimento associado ao cuidado com a saúde, educação, socialização, autonomia alimentar a afetividade. Mulheres negras engajadas politicamente, lutam incansavelmente pelo direito à sobrevivência de seus grupos comunitários em organizações profissionais, sindicais, grupos religiosos, políticos ao tempo que criam espaços de influência, com o objetivo de derrubar as barreiras e estruturas racistas e buscar a sobrevivência de seus coletivos.

Neusa Santos ${ }^{30}$ explica que ninguém nasce negra, a experiência emocional de ser negra em uma sociedade de classe, ideologia, estética, exigências e expectativas sociais construídas a partir da branquitude produz identidades

\footnotetext{
28 DAVIS, 2016 [1981]

29 INSTITUTO DE PESQUISA ECONÔMICA APLICADA, IPEA. 201 1. 39 p.: il.

30 SANTOS, 1990
} 
Nuñez, J. M. L.; Rios, J. A. V. P., Pedagogias de (re)existências do movimento de mulheres negras

subalternas. A violência ocorre quando a pessoa negra tenta de se ajustar pelo processo de embranquecimento e nunca se reconhece como negra assumindo a estética branca ou a máscara branca na tentativa de escapar a exclusão e violência a qual está submetida, como bem explica Fanon ${ }^{31}$.

Conceição Evaristo32 lembra que "a noite não adormece nos olhos das mulheres negras; há mais olhos que sono; onde lágrimas suspensas; virgulam o lapso; de nossas molhadas lembranças." O poema revela que as mulheres negras não se preocupam apenas com suas famílias, elas também vigiam os perigos que rondam suas comunidades. Igualmente o poema de Conceição Evaristo lembra o relato etnográfico feito por Ruth Landes no livro Cidade das Mulheres33, uma narrativa sobre o lugar das mães-de-santo no Candomblé e a condição sensível da afetividade, acolhimento, proteção e do poder das mulheres nos rituais em suas comunidades. As experiências comunitárias das mulheres negras, grande parte das vezes, remete à memória da infância, na relação com as/os mais velhas/os, avós, mães, tias, madrinhas, vizinhas e refere-se às memórias na comunidade.

Estas memórias valorizam o conhecimento acumulado que reside nas experiencias coletivas, nas brechas da insubmissão epistêmica que acompanha as diferentes organizações comunitárias. São mulheres que não se submeteram à exclusão e tem resistido e sustentado a dinâmica social, cultural, política e econômica em suas comunidades. Nada será feito em nosso nome, sem nós! Significa dizer que os movimentos sociais, especialmente o $M M N$, afirmam seu protagonismo na representação política e nas lutas por reparação histórica de mulheres e homens negros na sociedade. Nesta gramática de resistência é importante fortalecer os movimentos sociais antirracistas, antissexistas e antilgbtfóbicos para pensar a formação política e profissional de educadoras sob a perspectiva da desobediência em seus territórios e microestruturas de poder na comunidade dando sentido a (re)existência.

No final do ano de 2019 a RMNBA promoveu Encontros de Formação com o nome: AQUILOMBAR - Estado, Sociedade e as Mulheres Negras - Feminismo Negro

\footnotetext{
31 FANON, 1952

32 EVARISTO, 2008. P.21

33 LANDES, 2002
} 
Nuñez, J. M. L.; Rios, J. A. V. P., Pedagogias de (re)existências do movimento de mulheres negras

história e antecedentes ${ }^{34}$. Foram 2 encontros presenciais, mas com a crise sanitária em 2020, houve a necessidade de adaptar a formação para ocorrer virtualmente. O proposto foi discutir questões ligadas a forma como a covid 19 atingiu as mulheres negras e suas comunidades. Entre as temáticas discutidas estavam: "Ser Liderança em Tempos de Pandemia: Organização e Mobilização"; "Saúde da População Negra em 2020: Pandemia, Irmandade e Equilíbrio Emocional"; "Educação Básica: Impactos da Pandemia no contexto familiar e escolar".

Entre os relatos de lideranças que participaram das formações, transcrevemos alguns a seguir: "nós carregamos uma multidão conosco"; "nenhuma mulher preta ganha dinheiro somente para si"; "as necessidades das comunidades e o descaso do poder público pesam nos ombros e produzem um cansaço até da militância", "ainda bem que estamos aquilombadas em nossos terreiros e em nossos coletivos"; "é preciso entendermos que não estamos mais em uma normalidade democrática". A RMNBA foi o espaço de conforto, desabafo, acolhimento, partilha de ideias e reflexão política para que suas integrantes não se sentissem sós naquele momento crucial. A programação oferecida nas Lives reconheceu e valorizou a cultura local e a história cultural das mulheres negras baseada na proposta do Bem Viver, que origina-se da sabedoria ancestral indígena e da diáspora africana e busca uma cosmovisão comunitária voltada para um modo de vida que integra pessoas, natureza, modelo econômico, social e educacional, em uma visão de mundo com todas/os e para todas/os. O feminismo negro, projeto subjacente à RMNBA, é herdeiro desta visão utópica do Bem Viver e afirma que a "história está em nós, mulheres negras que tivemos nossas subjetividades forjadas na luta contra a opressão"35.

De início, os dados sobre a Covid-19, indicavam que todas/os estariam igualmente expostas/os à doença, mas o que foi demonstrado pelos estudos (após muita pressão dos movimentos sociais e de mulheres e homens negros, particularmente) foi que, apesar do vírus atingir as pessoas de forma igual, o impacto causado pelas desigualdades sociais na prevenção, propagação e tratamento da Covid-19, para a população negra, eram significativamente maiores, tendo em vista, o alto índice de mortalidade nas comunidades negras e

\footnotetext{
34 Anotações no Caderno de Campo de novembro de 2019 a julho de 2020

35 Carta das Mulheres Negras 2015
} 
Nuñez, J. M. L.; Rios, J. A. V. P., Pedagogias de (re)existências do movimento de mulheres negras

pobres ${ }^{36}$. O sistema de saúde não conseguiu dar conta da demanda provocada pela doença e em duas semanas, entre o final do mês de maio e o início de julho de 2020, a quantidade de pessoas negras que morreu por Covid-19 no Brasil quintuplicou 37 .

O racismo estrutura os elementos da vida social e tem uma ligação intrínseca com a economia, política, saúde, educação e com a forma como são elaboradas e implantadas políticas públicas voltadas para o enxugamento da máquina estatal e para a austeridade com gastos em áreas sociais prioritárias, esta situação, visivelmente, é incompatível com o incentivo à pesquisa, defesa do SUS, investimento em tecnologia, saneamento básico etc. Se tivéssemos direitos iguais e a sociedade brasileira não fosse estruturada pelo racismo, e livre de um Governo Genocida, talvez as instituições tivessem se movimentado em diferentes frentes, antes da situação agravar-se, como vemos agora em 2021. A população negra e periférica morreu pela Covid19 mais que o restante da população do país, devido aos modelos e mecanismos de poder que colocam principalmente mulheres negras e suas famílias na linha de frente das pessoas mais atingidas por toda miséria social ${ }^{38}$. Por isso, é vibrante assistir a juventude e as mulheres negras mobilizarem-se de forma solidária, insurgente, e organizada, para conseguir todo tipo de apoio desde cestas básicas, kits de higiene, confecção e distribuição de máscaras e equipamentos de proteção individual e trazer para suas comunidades formação política e debates sobre a pandemia em Lives, entre outras formas compatíveis com os tempos atuais.

No final das contas, como explica Lindinalva de Paula, Liderança da RMNBA, "a gente só pode contar com a gente mesma", "é de nós, por nós e para nós", pois "temos o olhar da afetividade, do cuidado com o bem viver e com a saúde das nossas"39. A mobilização na Rede junto às suas coletivas, tem sido fundamental para organização e sobrevivência durante este período de Pandemia.

Angela Davis ${ }^{40}$ afirma:

\footnotetext{
36MARASCIULO, 2020

${ }^{37}$ MUNIZ, FONSECA \& PINA, 2020/05

38 Ibidem, 2020/05

39 Registro em Caderno de Campo, junho 2020, autorizado pela liderança da RMNBA, através do termo de Autorização do Entrevistado, conforme recomendações do Conselho de Ética em Pesquisa.

40 DAVIS, 2016, p.17
} 
Nuñez, J. M. L.; Rios, J. A. V. P., Pedagogias de (re)existências do movimento de mulheres negras

precisamos nos esforçar para erguer-nos [umas às outras] enquanto subimos [...] devemos subir de modo a garantir que todas as nossas irmãs independentemente de classe social subam conosco, esta deve ser a dinâmica essencial da busca por poder.

Os grupos hegemônicos que estão historicamente no poder se apropriam da riqueza produzida e gerada pela maioria da população, não apenas a riqueza econômica, mas também a riqueza dos processos sociais e culturais com base na ideia da raça e nos benefícios que o racismo lhes confere, gera e alimenta em mecanismos de poder.

O ano de 2020 bateu recordes em feminicídio, segundo o Relatório Intitulado Violência Doméstica durante a Pandemia ${ }^{41}$ de Covid-19, do Fórum Brasileiro de Segurança Pública (FBSP), os casos de feminicídio cresceram 22,2\%, entre março e abril de 2020 em 12 estados. O documento coletou dados nos órgãos de segurança dos estados brasileiros. Além destes dados, o levantamento do "Um Vírus e Duas Guerras", projeto da parceria entre Amazônia Real, AzMina, \#Colabora, Eco Nordeste, Marco Zero Conteúdo, Portal Catarinas, e Ponte Jornalismo42 apontou que 1.005 mulheres perderam as vidas, vítimas de feminicídio, durante os meses da pandemia em 2020 no Brasil.

A média de três mortes por dia demonstrou explicitamente como o racismo e a misoginia produz necrobiopoder, que, conforme BENTO43 citando Foucault, qualifica e distribui os corpos em uma hierarquia que retira deles a possibilidade de reconhecimento como humanos. É dessa maneira que se decide quem deve ser eliminado e quem deve viver. Para que haja governabilidade desta matriz extremista em voga "produz-se interruptamente zonas de morte" e de poder soberano. "Há uma reiterada política de fazer morrer, com técnicas planejadas e sistemáticas" 44 .

Rogério Haesbaert45 afirma que os processos de des-reterritorialização nunca foram tão importantes como agora no combate à expansão do vírus. Durante a pandemia foram utilizadas várias formas de contenção e confinamento

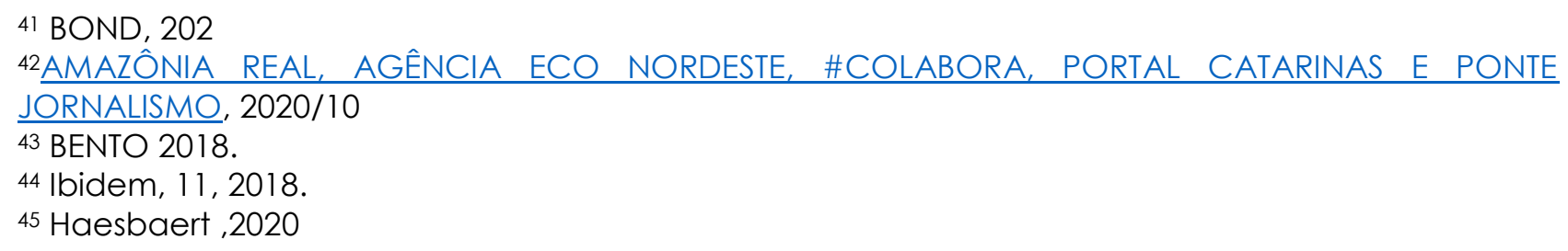


Nuñez, J. M. L.; Rios, J. A. V. P., Pedagogias de (re)existências do movimento de mulheres negras

geopolítico do vírus, em um mundo de tantas tecnologias onde o corpo-território é a derradeira fronteira a ser protegida do vírus, enquanto condição última e inevitável de nossa existência. O autor explica que precisamos pensar nas/os mais precarizadas/os, que só têm o corpo-território a ser defendido como derradeiro espaço sobre o qual ainda se tem algum controle. No pensamento decolonial feminista e indígena latino-americano, nosso corpo-território não está dissociado do território geopolítico, a apropriação territorial, em maior ou menor grau, faz parte de um sistema integral e indissociável.

A forma como o atual governo do Brasil agiu de forma negacionista com relação ao uso de máscaras, ao distanciamento social, a imposição de medicamentos para o tratamento precoce da Covid-19, condenados pelas organizações mundiais de saúde, foi a utilização pura e simples do necrobiopoder, ações incompatíveis com a defesa do Sistema Único de Saúde (SUS), a defesa da vida da população, os investimentos na pesquisa científica. Há um forte indicativo de um projeto genocida para as populações mais fragilizadas e rechaçadas da sociedade brasileira: as não brancas, indígenas, negras e periféricas, àquelas que mais precisam de políticas sociais. Todo este quadro, inflige modelos e mecanismos que colocam na linha de frente os territórios mais vulneráveis das cidades, das periferias distantes e sem infraestrutura, dos grupos subalternos e das pessoas mais atingidas por toda miséria social.

Suely Santos, liderança da RMNBA, integrante da campanha "Parem de Nos Matar" e do Movimento Negro Unificado (MNU), em uma entrevista ao site Koinonia, Presença Ecumênica e Serviço46, explica:

O momento de pandemia nos instigou a criar novas formas de comunicação, então, as lives têm sido a estratégia do movimento para circular as informações, buscar e dar ajuda. Semanalmente realizamos encontros temáticos para discutirmos os desafios e as dificuldades que estamos enfrentando. São encontros internos da Rede que, dentre outras coisas, servem como espaço para formação política.

Patrícia Santana, outra liderança da Rede na mesma entrevista aponta:

A pandemia abalou muito o movimento e as mulheres da Rede! Logo no começo, em abril, fizemos uma reunião ampliada para saber

46 Koinonia , 2020 
Nuñez, J. M. L.; Rios, J. A. V. P., Pedagogias de (re)existências do movimento de mulheres negras

como as mulheres estavam em questão de afetividade, que é uma coisa que trabalhamos bastante em nossas ações. Chegamos à conclusão que havia a necessidade de formar um grupo para ajudar as mulheres que são lideranças em seus espaços de atuação. Recebemos relatos de mulheres que tiravam coisas de seus armários para ajudar uma vizinha, coisa de mulher preta, né? Assim, surgiu o fundo emergencial das mulheres negras e a campanha "Cuidar de quem Cuida". Possibilitamos assistência na questão do auxílio emergencial e depois começamos as ações de solidariedade. Aos poucos fomos estruturando de forma digital nossas formações e agora estamos entrando na era de instrumentalizar essas mulheres para lidar com esse mundo digital, que é uma barreira a ser vencida. Ainda é novo para nós essa questão do pós-pandemia, as necessidades são tantas que estamos no modo comendo e assando, ainda é um caminho longo.

O que articula as mulheres negras, o que as conecta é este sentimento de contar umas com as outras, um dos lemas da Marcha das Mulheres Negras: "uma sobe e puxa a outra"47. A RMNBA, através de suas lideranças afirma: só a coletividade faz sentido para o feminismo negro. A mobilização das mulheres em suas comunidades foi e é fundamental na luta contra os efeitos sociais da Pandemia.

Conceição Evaristo dá um recado em sua palestra na Festa Literária de Paraty 48 :

Esse lugar é nosso por direito [...] Só estamos aqui por causa de um trabalho coletivo. Eu não cheguei aqui sozinha, mas por força de um grupo de mulheres negras. Quero deixar bem claro que não foi uma concessão.

Trazemos aqui a movimentação das mulheres negras carregadas em tantas escrevivências oferecidas pela maravilhosa intelectual ativista negra, Conceição Evaristo, que tanto nos tem ensinado com seus livros sobre estratégias de sobrevivência, condição, luta e resistência da mulher negra no Brasil.

\section{Considerações provisórias}

As novas gerações de educadoras negras intelectuais e ativistas fortalecidas no feminismo negro decolonial, apontam para a necessidade de permanecer lutando, mobilizando, agenciando coletivamente nossa luta contra as opressões

\footnotetext{
47 "Uma sobe e puxa a outra" foi uma expressão política, utilizada pelos movimentos de mulheres negras na Marcha de Mulheres Negras realizada, no ano de 2015, em Brasília.

48 FILGUEIRAS, 2017
} 
Nuñez, J. M. L.; Rios, J. A. V. P., Pedagogias de (re)existências do movimento de mulheres negras

que nos atravessam. Nossas experiências revelam memórias do coletivo no sentido de valorizar os conhecimentos que transbordam das grietas e da desobediência epistêmica. As mulheres têm sustentado a dinâmica social, cultural, política e econômica em nossa sociedade, nas lutas dos MMN, nas coletivas Quilombolas, nos movimentos comunitários, nos quais as mulheres têm sido as grandes provocadoras do deslocamento epistêmico desobediente e contra-hegemônico em direção ao feminismo negro e a emancipação social.

Conceição Evaristo nos ensina que "é tempo de formar novos quilombos, em qualquer lugar que estejamos"49. Por isto nos aquilombamos, para resistir a sociedade escravista, racista, misógina, LGBTfóbica, para reinventarmos próxis, teoria, ativismo, formação docente, luta política, afetividade em espaços coletivos de convivência, de produção material e imaterial de conhecimento em novas alternativas para pensar o futuro. Nos aquilombamos ao criarmos espaços coletivos de convivência, de conhecimento, nos aquilombamos para viver a perspectiva Ubuntu: eu sou porque nós somos!

Gente de variados movimentos, de ativismos sociais, dos movimentos antirracistas, dos MMN, da educação popular e das artes, com um pé dentro e outro fora da academia, contribuem para luta política de movimentos sociais antirracistas, antissexistas, de anti-discriminação baseada na orientação sexual e anticapitalistas. O pensamento de intelectuais e ativistas negras brasileiras como Lélia González, Nilma Lino Gomes, Angela Figueiredo, Claudia Cardoso, Ana Claudia Pacheco, Lindinalva de Paula, Sueli Santos, Helena Argolo, Karine Damasceno, Mara da Ponte, Denise Carrascosa, Thiffany Odara, entre outras tantas dos movimentos de mulheres negras, nos prepara para uma educação como prática de liberdade, nos ensinando a transgredir (HOOKS, 2013).

Ainda temos muito a alcançar e transformar, estamos nessa encruzilhada e nesse caminho, a pedagogia negra feminista e de resistência nos fortalece e nos coloca no lugar do debate público contemporâneo, o lugar emancipatório da mulher negra.

49 EVARISTO, 2020 
Nuñez, J. M. L.; Rios, J. A. V. P., Pedagogias de (re)existências do movimento de mulheres negras na Bahia em tempos de pandemia. ODEERE, v. 6, n. 01, jan./jun., p. 287-310, 2021.

https://doi.org/10.22481/odeere.v6i01.8500

\section{Referências}

Amazônia Real, Agência Eco Nordeste, \#Colabora, Portal Catarinas e Ponte Jornalismo I ODS 5. Um vírus e duas guerras. Disponível em https://projetocolabora.com.br/ods5/uma-mulher-e-vitima-de-feminicidio-acada-9-horas-durante-a-pandemia-no-brasil/ , 08 de outubro de 2020. Acesso em fevereiro de 2020.

BENTO Berenice. Necrobiopoder: Quem pode habitar o Estado-nação? Cad. Pagu $n^{\circ} .53$ Campinas, 2018. Epub June 11, 2018

BOND, Letycia. AgênciaBrasil, Casos de feminicídio crescem 22\% em 12 estados durante pandemia. Disponível em: Casos de feminicídio crescem $22 \%$ em 12 estados durante pandemia | Agência Brasil (ebc.com.br), 01/06/2020. Acesso em dezembro de 2020.

BRASIL. Decreto lei 7716, de 5 de janeiro de 1989. Define os crimes resultantes de preconceito de raça ou cor. Disponível em <http://www.planalto.gov.br/ccivil_03/lei/17 7161/htm> Acesso em 20 de janeiro de 2021.

BRASIL. Lei 10.639/2003, de 9 de janeiro de 2003. Altera a Lei no 9. 394, de 20 de dezembro de 1996. Diário Oficial da União, Poder Executivo, Brasília.

BRASIL. LEI No 12.288, DE 20 DE JULHO DE 20103 Institui o Estatuto da Igualdade Racial; altera as Leis nos 7.716, de 5 de janeiro de 1989, 9.029, de 13 de abril de 1995, 7.347, de 24 de julho de 1985, e 10.778, de 24 de novembro de 2003.

BRASIL. LEI No 12.990, DE 9 DE JUNHO DE 2014. DA Reserva aos negros $20 \%$

CARDOSO, Cláudia Pons. Outras falas: feminismos na perspectiva de mulheres negras brasileiras. Tese (doutorado) - Universidade Federal da Bahia, Faculdade de Filosofia e Ciências Humanas, Salvador, 2012. Disponível em https://repositorio.ufba.br/ri/bitstream/ri/7297/1/Outrasfalas.pdf Acesso em: 22 out. 2018.

CARNEIRO, S.; SANTOS, T. Mulher negra. São Paulo: Nobel/ Conselho Estadual da condição feminina, 1985.

Carta das Mulheres Negras 2015. Portal Geledés. Disponível em Carta das Mulheres Negras 2015 - Geledés (geledes.org.br). 18/11/2015. Acesso em janeiro de 2020.

COLLINS, Patricia Hill. Aprendendo com a outsider within*: a significação sociológica do pensamento feminista negro Revista Sociedade e Estado - Volume 31 Número 1 Janeiro/Abril 2016.

DAVIS, Angela. Mulheres, Cultura e Política. São Paulo: Boitempo, 2016.

DAVIS, Angela. Mulheres, raça e classe. S.Paulo: Boitempo, 2016 [1981]

EVARISTO, Conceição. Tempo de nos aquilombar. Xapuri, Cultura, Poemas \& Poesias, disponível em Tempo de nos aquilombar - xapuri.info, 07/01/2020. Acesso em fevereiro de 2020. 
Nuñez, J. M. L.; Rios, J. A. V. P., Pedagogias de (re)existências do movimento de mulheres negras

EVARISTO, Conceição. Poemas da recordação e outros movimentos. Belo Horizonte: Nandyala, 2008.

FANON, Frantz. Piel negra, máscaras blancas. Madrid. Akal. 2018 (Originalmente publicado em 1952.)

FILGUEIRAS, Mariana. Quando uma Mulher Negra se Mexe. Disponível em Quando uma mulher negra se mexe - Revista Continente. 04 de agosto de 2017. Acesso em fevereiro de 2021.

FIGUEIREDO, Angela. Epistemologia insubmissa feminista negra decolonial. Tempo e Argumento, Florianópolis, v. 12, n. 29, e 0102, jan./abr. 2020. http://dx.doi.org/10.5965/2175180312292020e0102

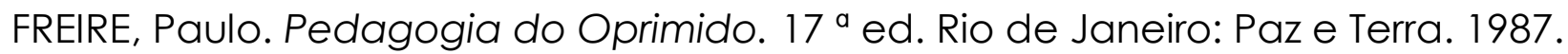

FREIRE, Paulo. Pedagogia dos sonhos possíveis. São Paulo: Paz e Terra, 2014.

GOHN, Maria Da Glória. Movimentos sociais na contemporaneidade, in Revista Brasileira de Educação v. 16 n. 47 maio-ago. 2011.

GOMES, Nilma Lino. O movimento negro educador: saberes construídos nas lutas por emancipação. Petrópolis, RJ: Vozes, 2017. 154 p.

GONZALEZ, Lélia. Por um feminismo afrolatinoamericano. Revista Isis Internacional (Santiago) 9: 133-141, 1988.

GONZALEZ, Lélia. Racismo e sexismo na cultura brasileira. In: Movimentos sociais urbanos, minorias e outros estudos, por L. A. Silva et al., 223-244. Ciências Sociais Hoje, n. 2. Brasília: Associaçã o Nacional de Pós-Graduaçã o e Pesquisa em Ciências Sociais/ANPOCS, 1983.

GROSFOGUEL, Rámon. Para uma visão decolonial da crise civilizatória e dos paradigmas da esquerda ocidentalizada. In: Decolonialidade e pensamento afrodiaspórico, organizado por Joaze Bernardino-Costa, Nelson Maldonado-Torres e Ramón Grosfoguel, p. 55-77. Belo Horizonte: Editora Autêntica, 2019.

HASENBAUG, Carlos. Discriminação e desigualdade social no Brasil. Rio de Janeiro: Graal, 1979.

HAESBAERT, Rogério. Entre a contenção e o confinamento dos corpos-território: reflexões geográficas em tempos de pandemia (II). Boletim Campineiro de Geografia, Campinas, Edição v. 10, n. 1, 2020. Disponível em http://agbcampinas.com.br/site/2020/rogerio-haesbaert-entre-a-contencao-e-oconfinamento-dos-corpos-territorio-reflexoes-geograficas-em-tempos-depandemia-ii/

HOOKS, Bell. Ensinando a transgredir: a Educação como prática de liberdade. Tradução de Marcelo Brandão Cipolla- São Paulo. 2013. Editora Martins Fontes, 2013.

Disponível

em http://generatech.org/sites/default/files/desarmando_la_escena.pdf. Consultado em setembro de 2019.

INSTITUTO DE PESQUISA ECONÔMICA APLICADA, IPEA. Retrato das desigualdades de gênero e raça / Instituto de Pesquisa Econômica Aplicada Com a participação 
de: ONU Mulheres, Secretaria de Políticas para as Mulheres (SPM), Secretaria de Políticas de Promoção da Igualdade Racial (Seppir). - 4ª ed. - Brasília: Ipea, 2011.39 p.: il.

INSTITUTO DE PESQUISA ECONÔMICA APLICADA. Dossiê Mulheres Negras: retrato das condições de vida das mulheres negras no Brasil, 2013. Disponível em: https://www.ipea.gov.br/retrato/pdf/revista.pdf Acesso em 28 jul de 2018.

LANDES, Ruth. A Cidade das Mulheres. Rio de Janeiro: Editora da UFRJ, Rio de Janeiro. 2002. $352 \mathrm{pp}$.

MALDONADO-TORRES, Nelson. Analítica da colonialidade e da decolonialidade algumas dimensões básicas. In: Decolonialidade e pensamento afrodiaspórico, organizado por Joaze Bernardino-Costa, Nelson Maldonado-Torres e Ramón Grosfoguel, p. 27-54. Belo Horizonte: Editora Autêntica, 2019.

MARASCIULO, Marília. Na pandemia de Covid-19, negros morrem mais do que brancos. Por quê? Na pandemia de Covid-19, negros morrem mais do que brancos. Por quê? - Revista Galileu | Sociedade (globo.com). 29 Mai 2020 - 15h42 Atualizado em 30 Mai 2020 - 15h33.

MUNIZ, Bianca; FONSECA, Bruno \& PINA, Ruth. Especial: Coronavírus. Pública, 6 de maio de 2020. Disponível em Número de negros mortos por coronavírus é cinco vezes maior no Brasil (apublica.org). Acesso em março de 2021.

NASCIMENTO, Abdias. O genocídio do negro brasileiro: processo de um racismo mascarado. São Paulo: Editora Perspectiva, 2016.

QUIJANO, Aníbal. Colonialidad del poder: eurocentrismo y América Latina. In LANDER, Edgardo (Org): La colonialidad del saber: eurocentrismo y ciencias sociales. Perspectivas latinoamericanas, CLACSO/UNESCO, Buenos Aires y Caracas, 2000, 2005 1-14.

RIOS, Jane Adriana Vasconcelos Pacheco Rios. Modos de habitar a profissão docente na Educação Básica: estado da arte das pesquisas na Bahia. Revista Perspectiva, Florianópolis, v. 38, n. 4 p. 01-24, out./dez. 2020

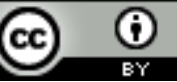

This work is licensed under a Licence Creative Commons Attribution 4.0 International License.

(i) Este trabalho está licenciado com uma Licença Creative Commons - Atribuição 4.0

Internacional. 